\title{
Effects of water vapor on the oxidation and the fracture strength of SiC layer in TRISO fuel particles
}

DOI:

10.1111/jace. 14723

\section{Document Version}

Accepted author manuscript

Link to publication record in Manchester Research Explorer

\section{Citation for published version (APA):}

Cao, F., Hao, W., Wang, X., Guo, F., Zhao, X., Rohbeck, N., \& Xiao, P. (2017). Effects of water vapor on the oxidation and the fracture strength of SiC layer in TRISO fuel particles. Journal of the American Ceramic Society. https://doi.org/10.1111/jace.14723

\section{Published in:}

Journal of the American Ceramic Society

\section{Citing this paper}

Please note that where the full-text provided on Manchester Research Explorer is the Author Accepted Manuscript or Proof version this may differ from the final Published version. If citing, it is advised that you check and use the publisher's definitive version.

\section{General rights}

Copyright and moral rights for the publications made accessible in the Research Explorer are retained by the authors and/or other copyright owners and it is a condition of accessing publications that users recognise and abide by the legal requirements associated with these rights.

\section{Takedown policy}

If you believe that this document breaches copyright please refer to the University of Manchester's Takedown Procedures [http://man.ac.uk/04Y6Bo] or contact uml.scholarlycommunications@manchester.ac.uk providing relevant details, so we can investigate your claim.

\section{OPEN ACCESS}




\section{Effects of water vapor on the oxidation and the fracture strength of SiC layer in TRISO fuel particles}

Fangcheng Cao ${ }^{1}$, Wei Hao ${ }^{1}$, Xin Wang ${ }^{2}$, Fangwei Guo ${ }^{1, *}$, Xiaofeng Zhao ${ }^{1, *}$, Nadia Rohbeck ${ }^{3}$ and Ping Xiao ${ }^{3}$

${ }^{1}$ Shanghai Key Laboratory of Advanced High-temperature Materials and Precision Forming,

Shanghai Jiao Tong University, Shanghai 200240, China

${ }^{2}$ Konca Solar Cells Co., Ltd, Jiangsu 214174, China

${ }^{3}$ School of Materials, University of Manchester, Manchester M13 9PL, United Kingdom

*Author to whom correspondence should be addressed.

E-mail: fwguo1984@163.com and xiaofengzhao@sjtu.edu.cn. 


\begin{abstract}
Steam oxidation of silicon carbide (SiC) layer in nuclear fuel particles were performed in flowing argon-water vapor mixture with a total pressure of 1 bar at 1173-1673 K. Both the phase composition and the microstructure of the oxide scale on the SiC layer varied with the oxidation temperature. Reaction rates of water vapor with the SiC layer were determined by measuring the oxide scale thickness. It was found that the oxidation of SiC layer follows the parabolic law. The activation energy was calculated to be $103 \pm 11 \mathrm{~kJ} / \mathrm{mol}$. It is proposed that the rate determine step of the oxidation is the diffusion of water vapor molecules in the oxide scale. The fracture strength of SiC shell after steam oxidation was evaluated using a crush test. The fracture strength decreased with the increase of the oxidation temperature due to the thinning of the $\mathrm{SiC}$ layer.
\end{abstract}

Keywords: Fuel particle; Silicon carbide; Steam oxidation; Fracture strength 


\section{Introduction}

High-temperature gas-cooled reactor (HTGR) is one of the most promising candidates for the future generation-IV nuclear system due to its inherently safe design ${ }^{[1]}$. The primary safety assurance comes from the HTGR nuclear fuel element that is based on the tristructural-isotropic (TRISO) type fuel particle. Generally, the spherical fuel kernel in a TRISO particle is coated with four successive layers, namely a porous carbon buffer layer, an inner dense PyC (IPyC) layer, a SiC layer and an outer dense PyC (OPyC) layer ${ }^{[2]}$. The TRISO system is designed not only to retain all fission products during neutron irradiation but also to withstand the thermo-mechanical stresses experienced during service. The SiC layer is a key component for the integrity of TRISO particles and acts as a pressure vessel to accommodate gaseous fission releases.

During operation, the concentration of contaminants in the coolant-helium is maintained at a low level by cycling a certain fraction of the coolant through a purification system. However, the fuel elements may be oxidized by low concentration oxidants (e.g., $\mathrm{H}_{2} \mathrm{O}, \mathrm{CO}_{2}, \mathrm{O}_{2}$ ) presented in the helium ${ }^{[3]}$. The ingress of steam into the coolant from a damaged heat exchanger is probably the most likely accident which would destroy the integrity of the layers of TRISO particles ${ }^{[4]}$. Once the graphite matrix of the compacts or pebbles has been oxidized away and the SiC shell of the TRISO is exposed, the steam oxidation would cause degradation of the mechanical and thermal properties of the outer layers and increase the failure probability, and in the worst case results in a rapid release of volatile fission products (e.g., Xenon and Krypton) ${ }^{[5,6]}$. Much more than a cost issue, it can cause disastrous safety problems. On the other hand, the potential application of TRISO particles in other reactors (e.g., light water reactor) has attracted considerable interest ${ }^{[7]}$. Therefore, an investigation of the high temperature steam oxidation of SiC layers in TRISO particles is important for assessing the safety of the reactor. 
The steam oxidation of $\mathrm{SiC}$ (e.g., sintered $\alpha$-SiC, high purity $\beta$-SiC and SiC-based composites) has attracted tremendous research interest for decades ${ }^{[8,9,10]}$, since SiC component has been developed for the hot sections in gas turbines, e.g., turbine blades. The water vapor is a major cause for the failure of SiC-based ceramics in combustion environments. Furthermore, the SiC layers on spherical substrates exhibited different microstructure from that of the bulk $\mathrm{SiC}{ }^{[11]}$. Some researchers have reported high temperature oxidation behavior of TRISO particles in air or oxygen ${ }^{[12]}$. Recently, the oxidation of the SiC layer in TRISO particles in flowing steam environments at 1737-1973 K was also studied ${ }^{[13]}$. But the effects of oxidation on the mechanical strength of SiC layers in TRISO particles still need to be further clarified.

In the present work, the oxidation of the SiC layers in TRISO particles was investigated in steam at a temperature range of 1173-1673 K. The composition and microstructure of the SiC layers after steam oxidation were characterized and analyzed. The oxidation kinetics of the SiC layer was studied with the aim of predicting the SiC degradation rate in case of a steam ingress accident in operation. The fracture strength of the SiC layer after steam oxidation was further investigated, which is essential for the design and performance analysis of TRISO particles.

\section{Experimental procedure}

The TRISO particles were provided by the University of Manchester made by fluidised bed chemical vapor deposition using zirconia particles with a diameter about $500 \mu \mathrm{m}$ as simulated kernels ${ }^{[14]}$. To study the oxidation behavior of SiC layer, the TRISO particles were originally produced without the OPyC layer. The average thickness of the buffer, IPyC and SiC layers were $200 \mu \mathrm{m}, 40 \mu \mathrm{m}$ and $24 \mu \mathrm{m}$, respectively.

\subsection{Steam oxidation}


Steam oxidation treatments were performed at a temperature range of 1173-1673 K using argonwater vapor mixtures with a total pressure of 1 bar. The oxidation time varied from $4 \mathrm{~h}$ to $48 \mathrm{~h}$. The furnace was horizontally held with an alumina tube and has a $20 \mathrm{~mm}$ long hot zone. The alumina tube has an inner cross sectional area of $3.8 \times 10^{-3} \mathrm{~m}^{2}$, a wall thickness of $5 \mathrm{~mm}$ and a length of $1 \mathrm{~m}$. The flow rate of the high-purity argon stream was kept at a constant value, which was calculated to be $8.7 \times 10^{-4} \mathrm{~m} / \mathrm{s}$. The import of water vapor was accomplished by bubbling the argon through a bottle of deionized water that was heated in the oil bath thermostat at $363 \mathrm{~K}$. The water content in the mixed gas was controlled by the argon flow rate as well as the water temperature ${ }^{[15]}$. The water content in the gas mixture was measured by flowing the moisturized argon at a rate of $8.7 \times 10^{-4} \mathrm{~m} / \mathrm{s}$ through a bottle of concentrated sulfuric acid desiccant for a given time. The weight gain of the desiccant due to the absorption of water could then be converted to the water concentration of the gas mixture. The flow rate of the gas mixture through the alumina tube at room temperature was calculated to be $1.4 \times 10^{-3} \mathrm{~m} / \mathrm{s}$. Table 1 summarizes the basic parameters for the steam oxidation setup. During the oxidation experiments, the pipes flowed by saturated gas mixture were kept warmer than the dew point of the water saturated argon $(\sim 325 \mathrm{~K}){ }^{[16]}$ to prevent the condensation of water vapor. The alumina tube was purged under steam atmosphere at $1473 \mathrm{~K}$ for $48 \mathrm{~h}$ before the steam oxidation tests to minimize the effects of impurities. The TRISO particles were placed on the platinum crucible in the middle of the hot zone. The TRISO particle samples which adhered on the platinum crucible especially at high temperature were excluded in the performance characterization in order to avoid any effects of interaction between the platinum and SiC. ${ }^{[17,18]}$ To check if any $\mathrm{SiO}_{2}$ volatilization occurred during the high temperature steam oxidation, tests were carried out to measure the weight change of the $\mathrm{SiO}_{2}$ bulk sample ( $\alpha$-cristobalite, $20 \mathrm{~mm} \times 10 \mathrm{~mm} \times 5 \mathrm{~mm}$ ) after steam oxidation using a balance with an accuracy of $0.01 \mathrm{mg}$. For comparison, parallel experiments were conducted in dry air at $1473 \mathrm{~K}$. 


\subsection{Characterization}

After oxidation, the TRISO particles were embedded in epoxy and ground using the conventional metallographic approach to their middle plane to form a half sphere. Hemispherical samples were retrieved from the epoxy by using acetone to dissolve the epoxy and then heated in air at $1073 \mathrm{~K}$ for $8 \mathrm{~h}$ to burn off the PyC layers to obtain free-standing hemispherical SiC shells.

The microstructure of the SiC layers in TRISO particles was characterized using a scanning electron microscope (SEM) (Inspect F50, FEI, US), which was equipped with an energy dispersive spectroscopy (EDS). Both the thickness of $\mathrm{SiC}$ and oxide scale on the $\mathrm{SiC}$ layer after oxidation was measured at approximately twenty points at cross sections of TRISO particles. The phase of reactive products on the surfaces of the TRISO particle were examined by X-ray diffraction (XRD) (Ultima IV, Rigaku, Japan) and by Raman spectroscopy (LabRAM HR Evolution, Horiba, France) with incident laser beam of $532 \mathrm{~nm}$ (Nd:YAG).

The fracture load measurements of SiC shells were performed using the modified crush test and the detailed process can be found in the previous study ${ }^{[19]}$. The crush test was carried out in a universal material testing machine (Z020, Zwick/Roell, Germany). For each oxidation condition, at least 30 specimens were tested at room temperature with a crosshead speed of $5 \times 10^{-3} \mathrm{~m} / \mathrm{s}$. A schematic testing illustration is shown in Fig. 1. The outer radius $(r)$ and thickness $(\delta)$ of the SiC shell were measured before testing. The specimen was diametrically loaded between a plunger and a steel base with an annealed brass foil ( $\left.5 \mathrm{~mm} \times 5 \mathrm{~mm} \times 0.5 \mathrm{~mm}, 68 \mathrm{HV}_{0.05}\right)$. The brass insert was used to produce a uniform stress distribution under the load contact area. The maximum load before crushing was regarded as the fracture load $(F)$. The radius $\left(r_{0}\right)$ of the load contact area was measured from the impression formed on the brass foil. 


\section{Results}

\subsection{The microstructure of the SiC layers}

Figure 2 shows the microstructure of the SiC layer before and after the steam oxidation at different temperature for $24 \mathrm{~h}$. The as-deposited SiC layer exhibits faceted morphology on the outer surface and columnar grains on the cross section (Fig. 2a). No significant variation in the morphology was observed after steam oxidation at $1173 \mathrm{~K}$, while a mosaic oxide layer appeared at $1273 \mathrm{~K}$ (Fig. 2b). This means that for an oxidation time of $24 \mathrm{~h}$, the SiC layer has a good steam oxidation resistance below $1173 \mathrm{~K}$ and apparent oxidation occurs at $1273 \mathrm{~K}$. After steam oxidation at $1373 \mathrm{~K}$, the surface morphology changed from multifaceted to smooth with the formation of a thin oxide layer. When the oxidation temperature was further increased to $1473 \mathrm{~K}$, the surface of the oxide scale appeared a spherulitic structure (Fig. 2c), which is characteristic for the cristobalite formation ${ }^{[9]}$. The elements $\mathrm{C}, \mathrm{O}$ and Si were detected by the EDS (inset of Fig. 2c). The samples steam oxidized at $1673 \mathrm{~K}$ showed that the $\mathrm{SiO}_{2}$ grains grew from elongated grains to uniformly spherical grains (Fig. 2d). The spallation of the $\mathrm{SiO}_{2}$ scale was also observed (inset of Fig. 2d). It was found that most of the pores exhibited an elliptical shape, which tended to line up parallel to the surface of the SiC layer. As comparison, only a thin $\mathrm{SiO}_{2}$ film was formed on the surface of $\mathrm{SiC}$ layer for samples oxidized in dry air at $1473 \mathrm{~K}$ (Fig. 2e). Impurities in the $\mathrm{SiO}_{2}$ scale of all the samples were not detectable by EDS. Therefore, it can be inferred that the presence of water vapor promoted the crystallization of the amorphous $\mathrm{SiO}_{2}$ and the oxidation rate of $\mathrm{SiC}$ layer.

\subsection{Phase composition of SiC layers}

Figure 3 shows the effect of oxidation temperature on the XRD patterns of TRISO particles after oxidized for $24 \mathrm{~h}$ under different conditions. Three typical phases could be identified in the XRD 
pattern of the as-deposited sample, namely the $\mathrm{ZrO}_{2}$ kernel, the $\mathrm{PyC}$ layer and SiC layer. At temperatures below $1373 \mathrm{~K}$, no oxide phase was observed. After oxidation at $1473 \mathrm{~K}$, diffraction peaks corresponding to the $\mathrm{SiO}_{2}$ phase could be detected with weak intensity. To amplify the small peaks, the Y axis was plotted to the sqrt(Intensity) (Fig. 3b). The relative intensity of the diffraction peaks of the $\mathrm{SiO}_{2}$ phase tended to increase with the increase of the oxidation temperature. Combined with Fig. 2, the results showed that the $\mathrm{SiO}_{2}$ scale formed was amorphous at 1273-1373 $\mathrm{K}$ and gradually crystalized at temperatures above $1473 \mathrm{~K}$. The major crystalline $\mathrm{SiO}_{2}$ phase was detected to be $\alpha$-cristobalite, which then partially transformed to tridymite after oxidation at 1673 K. The literature report that impurities could promote the transformation of cristobalite to tridymite at $1473 \mathrm{~K}$ in steam oxidation ${ }^{[19]}$. However, this effect was not observed in this study. In contrast, no $\mathrm{SiO}_{2}$ phase was detected in the samples oxidized in dry air at $1473 \mathrm{~K}$. It indicates that the crystallization of amorphous $\mathrm{SiO}_{2}$ is accelerated by the presence of water vapor ${ }^{[20]}$, which might further account for the accelerated oxidation rate.

Raman spectra were also used to characterize the phase composition of TRISO particles after steam oxidation. Significant differences in the Raman spectra at ranges of $100-550 \mathrm{~cm}^{-1}$ and $1200-$ $1850 \mathrm{~cm}^{-1}$ were observed, as shown in Fig. 4. The peaks at $110 \mathrm{~cm}^{-1}, 230 \mathrm{~cm}^{-1}$ and $417 \mathrm{~cm}^{-1}$ correspond to the existence of $\mathrm{SiO}_{2}$. The $\mathrm{SiO}_{2}$ peaks varied from broad peaks to sharp peaks as the oxidation temperature increased above $1373 \mathrm{~K}$. The intensities of the oxide peaks increased consistently with the increase of the oxide layer thickness ${ }^{[21]}$. The bands of SiC (796 and $\left.972 \mathrm{~cm}^{-1}\right)$ were visible (Fig. 4a), so the laser should have penetrated the full thickness of the oxide scale ( $>5$ $\mu \mathrm{m}$ at $1673 \mathrm{~K}$ ) after oxidation. No obvious $\mathrm{SiO}_{2}$ phase was detected in the samples oxidized in dry air at $1473 \mathrm{~K}$ by Raman spectroscopy. These results are consistent with the XRD analyses. In addition, the $\mathrm{D}\left(1350 \mathrm{~cm}^{-1}\right)$ and $\mathrm{G}$ band $\left(1600 \mathrm{~cm}^{-1}\right)$ which are the first order peaks of carbon also 
appeared with the increase of oxidation temperature above $1473 \mathrm{~K}$. Though the $\mathrm{G}$ band is somewhat overlapping with the second order band of SiC that is between $1400 \mathrm{~cm}^{-1}$ and $1800 \mathrm{~cm}^{-1}$, the obvious D band confirms the presence of amorphous carbon ${ }^{[22]}$. The low intensity of the D and G band indicates a small proportion of carbon at the interface of the $\mathrm{SiC} / \mathrm{SiO}_{2}$ after high temperature oxidation of $\mathrm{SiC}$, which was identified in previous research by other methods (e.g., Auger electron

spectroscopy) ${ }^{[23,24,25]}$. However, no more carbon band was observed in the samples after oxidation at $1673 \mathrm{~K}$, at which temperature any carbon formed at the interface of $\mathrm{SiC} / \mathrm{SiO}_{2}$ was likely oxidized after the spallation of the external oxide layer.

\subsection{Steam oxidation of SiC layers}

To study the oxidation behavior of the SiC layers in TRISO particles, oxidation tests were further performed at different temperatures with different time. The oxide layer thickness as a function of the oxidation time is shown in Fig. 5. When the temperature was below $1173 \mathrm{~K}$, the changes of the surface morphology of the SiC layer were barely noticeable. It appears no measurable oxidation occurred at $1273 \mathrm{~K}$ and $24 \mathrm{~h}$ exposure, due to slow kinetics. At $1373 \mathrm{~K}$, the $\mathrm{SiO}_{2}$ layer was thin and the thickness increased slowly. But the thickness of the oxide layer increased significantly with the increase of oxidation time at temperatures above $1473 \mathrm{~K}$. It was found that the oxidation exhibited significant difference in terms of the morphology and the crystalline phase of the oxide scale between in dry air and in steam at the same temperature (e.g., $1473 \mathrm{~K}$ ). This observation further supported the hypothesis that water vapor can effectively accelerate the oxidation of SiC layer.

\subsection{Fracture strength of SiC shells}

Figure 6 shows the measured fracture load in the form of Weibull plots. It can be found that there was significant variation in the fracture load for individual particle for the same batch of samples. 
The mean fracture loads were in the range of 3.7-4.9 $\mathrm{N}$ and slightly decreased with the increase of the oxidation temperature, which could be attributed to the thinning of SiC shells. The Weibull modulus determined from the fracture load plots were in the range of 2.3-2.6, which also decreased with the increase of the oxidation temperature. The relation of the SiC layer thickness to the fracture load of TRISO particles is shown in Fig. 7 in comparison with the previous study using annealed aluminium as inset metal ${ }^{[26]}$. In contrast, crush test using brass in this study resulted in a significantly lower fracture load than that using aluminium $(20 \mathrm{HV}){ }^{[26]}$, which could be attributed to the hardness of the insert metal. Finite element analysis has predicted that a small conical volume of highly stressed zone at the inner surface of $\mathrm{SiC}$ would be produced with a hard insert metal ${ }^{\text {[27] }}$.

Furthermore, it is also important to calculate the fracture strength of SiC layer, since it is an important parameter used in the modelling of the failure of TRISO particles. The detailed calculation procedures of the fracture strength were reported in previous study ${ }^{[28]}$. Due to the complexity of the solutions, it was traditionally expressed by using following equations ${ }^{[19]}$. A brief summary is shown in Eq. (1)-(10) ${ }^{[18,28]}$ :

$$
\begin{aligned}
& C_{1}=0.2205-0.04 \mu-0.0115 \mu^{2} \\
& C_{2}=1.2044 e^{(-1.2703 \mu)} \\
& \mu=r_{0}\left[\frac{12\left(1-v^{2}\right)}{r^{2} \delta^{2}}\right]^{\frac{1}{4}} \\
& \sigma_{\text {membrane }}=-C_{1} \frac{F \sqrt{1-v^{2}}}{\delta^{2}} \\
& \sigma_{\text {bending }}=-C_{2} \frac{F \sqrt{1+v}}{\delta^{2}}
\end{aligned}
$$




$$
\sigma_{f}^{L}=\sigma_{\text {membrane }}-\sigma_{\text {bending }}
$$

where $C_{1}$ and $C_{2}$ are the intermediate coefficients, $\mu$ is the intermediate variable, $v$ is the Poisson ratio, $r$ is the outer diameter of shell, $\delta$ is the thickness of shell, $F$ is the applied load, $r_{0}$ is the radius of the circular contact area, $\sigma_{\text {membrane }}$ is the maximum membrane stress, $\sigma_{\text {bending }}$ is the maximum bending stress and $\sigma_{f}^{L}$ is the local fracture strength of the specimen, which presents the maximum tensile stress at the inner surface of the shell.

For brittle materials, the fracture strength is best considered as a probability distribution value rather than a fixed value. The distribution of local fracture strength is generally analyzed by the Weibull distribution function. Using Weibull's two-parameter distribution, the cumulative probability of failure $(P)$ is presented by ${ }^{[19,28]}$ :

$$
P=1-\exp \left[-S_{E}\left(\frac{\sigma_{f}}{\sigma_{0}}\right)^{m}\right]
$$

where $\sigma_{f}$ is the fracture strength; $m$ is the Weibull modulus; $\sigma_{0}$ is the characteristic strength and $S_{E}$ is the size effect factor, respectively. The size effect factor is presented as: $S_{E}=\pi r_{0}^{2}{ }^{[19,28]}$. By taking the logarithm twice, Eq. (7) can be rewritten in a linear form ${ }^{[19,28]}$ :

$$
\ln \left(\ln \left(\frac{1}{1-P}\right)\right)=m \cdot \ln \sigma_{f}+\ln \left(\frac{S_{E}}{\sigma_{0}^{m}}\right)
$$

The Weibull modulus and scale parameter can be obtained from the slope and intercept parameters in Eq. (8). And a conservative probability estimator of the following equation was selected $^{[19,28]}$ : 


$$
P_{i}=\frac{i}{N+1}
$$

where $P_{i}$ is the probability of failure for the $i$ th-ranked strength, and $N$ is the sample size. The calculation of the fracture strength for the full spherical shell $\left(\sigma_{f}^{F}\right)$ is based on the mean crosssectional divot area and the mean total inner surface area, which is given as ${ }^{[19,28]}$ :

$$
\sigma_{f}^{F}=\left[\frac{\pi r_{0}^{2}}{4 \pi(r-\delta)^{2}}\right]^{\frac{1}{m}} \sigma_{f}^{L}
$$

Therefore, the local fracture stress is converted to the value for a full-size spherical shell, which is regarded as the fracture stress representing the whole shell under uniform internal pressurization. Also, the coefficient $\pi r_{0}^{2} / 4 \pi(r-\delta)^{2}$ can be called the scaling factor for size effect between the localized loading and the uniform internal pressurization ${ }^{[19,28]}$.

Figures 8 and 9 present the calculation results for the local fracture stress $\left(\sigma_{f}^{L}\right)$ and the fracture stress for full spherical shells $\left(\sigma_{f}^{F}\right)$. The Weibull modulus was obtained by linearly fitting the spots, which shows the width and magnitude of the strength distribution. Table 2 summarizes all the relevant results of the crush tests. The local fracture stress data (Fig. 8) were converted to the fracture stresses for full spherical shells (Fig. 9) using the size effect Eq. (10). The mean values of the local fracture stress were in the range 1501-1638 MPa, while those for the full-size shells under internal pressurization were in the range 553-729 MPa. As listed in Table 2, the scaling factors for size effect between the locally loaded area and the whole inner surface area of the full spherical shell were in range of 2.3-2.7. Both the fracture strength and Weibull modulus tended to decrease with the increase of the oxidation temperature. 


\section{Discussion}

\subsection{Oxidation kinetics of SiC layers}

Thermodynamic calculations show that the oxidation of $\mathrm{SiC}$ in water vapor occurs primarily via the reactions ${ }^{[29,30]}$ :

$$
\begin{array}{ll}
\mathrm{SiC}(\mathrm{s})+3 \mathrm{H}_{2} \mathrm{O}(\mathrm{g})=\mathrm{SiO}_{2}(\mathrm{~s})+3 \mathrm{H}_{2}(\mathrm{~g})+\mathrm{CO}(\mathrm{g}) & (\text { for } \mathrm{T}>1400 \mathrm{~K}) \\
\mathrm{SiC}(\mathrm{s})+2 \mathrm{H}_{2} \mathrm{O}(\mathrm{g})=\mathrm{SiO}_{2}(\mathrm{~s})+\mathrm{CH}_{4}(\mathrm{~g}) \quad(\text { for } \mathrm{T}<1400 \mathrm{~K})
\end{array}
$$

The $\mathrm{SiO}_{2}$ scale formed on the surface of $\mathrm{SiC}$ may simultaneously volatilize with the presence of water vapor under certain conditions particularly with a high gas flow rate (e.g., $15-30 \mathrm{~m} / \mathrm{s}^{[31]}$ ) by forming silicon hydroxide or silicon oxyhydroxide species ${ }^{[31,32]}$. In this study, the possibility of $\mathrm{SiO}_{2}$ scale volatility in water vapor can be assumed to be negligible, which is mainly based on the following three observations.

First, the weight loss rate of the $\mathrm{SiO}_{2}$ bulk sample after steam oxidation exposure were $5.8 \times 10^{-8}$ $\mathrm{g} /\left(\mathrm{m}^{2} \cdot \mathrm{s}\right)$ for $144 \mathrm{~h}$ at $1473 \mathrm{~K}$. It was neglected as being roughly two orders of magnitude smaller than the values reported previously ${ }^{[17,31,32]}$. Second, the oxide thickness as a function of oxidation time fits well with the parabolic kinetics equation (Fig. 5), which indicates that volatilization of the $\mathrm{SiO}_{2}$ scale was negligible. And third, the volatilization of the $\mathrm{SiO}_{2}$ scale would result in the paralinear kinetics, showing a stabilized thickness of the oxide layer (e.g., 30-50 h in 50 vol\% $\mathrm{H}_{2} \mathrm{O} / \mathrm{O}_{2}$ mixtures with a rate of $4.4 \times 10^{-2} \mathrm{~m} / \mathrm{s}$ at $\left.1473-1673 \mathrm{~K}\right)^{[32]}$, which is not the case in the present study, as shown in Fig. 5. In addition, the paralinear kinetics predicts that the linear volatilization rate of $\mathrm{SiO}_{2}\left(k_{l}\right)$ has the following parameter dependence ${ }^{[32,33]}$ : 


$$
k_{l} \propto p_{H_{2} O}^{2} \frac{v^{1 / 2}}{P_{\text {total }}^{1 / 2}}
$$

where $p_{\mathrm{H}_{2} \mathrm{O}}$ is the partial pressure of water vapor; the $p_{\text {total }}$ is the total pressure of gas mixture and $v$ is the gas flow rate. A previous study had reported that the volatility effect of $\mathrm{SiO}_{2}$ was barely discernible for a gas flow rate of $4 \times 10^{-2} \mathrm{~m} / \mathrm{s}$ (50 \% water vapor/1 bar total pressure/1473-1673 K) ${ }^{\text {[33] }}$. In this study, the total pressure of gas mixture was 1 bar with 38 vol\% water vapor at a low gas flow rate of $1.4 \times 10^{-3} \mathrm{~m} / \mathrm{s}$. Therefore, the volatilization of $\mathrm{SiO}_{2}$ in this study can be neglected.

Ignoring early stages that could be chemical reaction rate-controlling for a very short period $(<1 \mathrm{~h}$ ${ }^{[8,34]}{ }^{[35]}$, the SiC oxidation is reported to be determined by two mechanisms: parabolic oxidation and linear $\mathrm{SiO}_{2}$ volatilization, respectively ${ }^{[17,30]}$. In this study, the $\mathrm{SiO}_{2}$ volatilization can be negligible. Then the oxidation of $\mathrm{SiC}$ was expected to follow the parabolic law, which is expressed

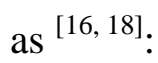

$$
x^{2}=k_{p} t
$$

where $x$ is the oxide thickness; $t$ is the oxidation time; $k_{p}$ is the parabolic rate. By fitting the $\mathrm{SiO}_{2}$ thickness with the oxidation time using Eq. (14), the parabolic rates were obtained and summarized in Table 3. The oxidation parabolic rate of SiC significantly increased with the increase of temperature. And the oxidization rate was about four times of that obtained in dry air at $1473 \mathrm{~K}$ (Table 3). Previous investigations had proposed that water vapor can destroy the $\mathrm{SiO}_{2}$ network by replacing the strong $[\mathrm{Si}-\mathrm{O}-\mathrm{Si}]$ bond with a weaker $[\mathrm{Si}-\mathrm{OH} \mathrm{OH}-\mathrm{Si}]$ bond, resulting in a decrease in the viscosity and density of the $\mathrm{SiO}_{2}$ scale ${ }^{[18,32]}$. Thereby, the process can accelerate the permeation and diffusion of the water vapor in $\mathrm{SiO}_{2}$ scale as well as accelerate the crystallization of the 
amorphous $\mathrm{SiO}_{2}$ and consequently promote the $\mathrm{SiC}$ oxidation. Table 3 compares the parabolic oxidation rates in this study with those in the previous study which also neglected the volatilization and followed the parabolic law ${ }^{[16]}$. The parabolic oxidation rate at $1473 \mathrm{~K}$ in the study is close to that in the previous study and then become much smaller than that in the previous study at above $1573 \mathrm{~K}^{[16]}$. The difference can be explained by that in the previous study there were contamination effects of sodium and aluminum as detected by EDS, which would highly accelerate the crystallization of the oxide scale and increase the oxidation rate ${ }^{[16,36]}$. And the effects of impurities become more significant at higher temperature, as the parabolic oxidation rate in this study was less than half of that in the previous study at $1673 \mathrm{~K}$.

The temperature dependence of the rate constants can be described using the Arrhenius law ${ }^{[37]}$ :

$$
k=K_{0} \cdot \exp \left(\frac{-E_{a}}{R T}\right)
$$

where $k$ is the rate constant, which is corresponding to the parabolic oxidation rate in this study, $K_{0}$ is the frequency factor, $E_{a}$ is the activation energy, $\mathrm{R}$ is the ideal gas constant $\left(\mathrm{R}=8.314 \times 10^{-3}\right.$ $\mathrm{kJ} /(\mathrm{mol} \cdot \mathrm{K}))$, and $T$ is temperature. Using Eq. (15) to fit the experimental data, the activation energy $\left(E_{a}\right)$ can be estimated. Figure 10 shows the Arrhenius plot of the obtained parabolic rate constant $\left(k_{p}\right)$ versus temperature. The activation energy of the parabolic rate constants above $1373 \mathrm{~K}$ was calculated to be $103 \pm 11 \mathrm{~kJ} / \mathrm{mol}$. This value is much smaller than the value of $428 \mathrm{~kJ} / \mathrm{mol}$ reported in the previous study, which value was suggested to correspond to the chemical reaction at the SiC surface $^{[9]}$. The oxidation mechanism of the rate-controlling diffusion of SiO or CO molecules was also excluded, which was previously reported for higher activation energies at higher temperatures [34]. In this study, a smaller activation energy (103 $\pm 11 \mathrm{~kJ} / \mathrm{mol})$ was derived, which is close to the activation energy for the diffusion of water vapor in amorphous $\mathrm{SiO}_{2}(75 \mathrm{~kJ} / \mathrm{mol})^{[9]}$. Therefore, it is 
likely that the rate-controlling step is the diffusion of water vapor in $\mathrm{SiO}_{2}$ scale. The activation energy obtained in this study also falls into the range of the activation energies of $28-156 \mathrm{~kJ} / \mathrm{mol}$ reported for $\mathrm{SiC}$ at up to $1473 \mathrm{~K}$ for wet oxygen oxidation, which was controlled by the diffusion of oxidant ${ }^{[30]}$. Nevertheless, the less temperature dependence of SiC oxidation in water vapor indicates that the molecular permeation mechanism is more predominant than a diffusion mechanism that involves charged species ${ }^{[30]}$. The calculated activation energy in this work is smaller than that of the oxidation of SiC at $1473-1673 \mathrm{~K}$ in air (about $145 \mathrm{~kJ} / \mathrm{mol}$ ) ${ }^{[12]}$, in which the rate-controlling step is the diffusion of oxygen in $\mathrm{SiO}_{2}$. The difference in the activation energy may due to a higher diffusion rate and solubility for water than for oxygen in the $\mathrm{SiO}_{2}$ scale ${ }^{[9,30]}$.

\subsection{Effect of steam oxidation on the microstructure of SiC layers}

Under oxidative condition, the integrity of the $\mathrm{SiO}_{2}$ layer is an important factor for the oxidation resistance of the SiC layer. However, above $1473 \mathrm{~K}$, cracks in the oxide layer and even spallation of the oxide layer were observed, which were probably caused by the following reasons: First, the linear thermal expansion coefficient of the cristobalite $\left(21 \times 10^{-6} / \mathrm{K}\right)$ is higher than that of the $\mathrm{SiC}$ $\left(4.7 \times 10^{-6} / \mathrm{K}\right)^{[38]}$, thus the cristobalite $\mathrm{SiO}_{2}$ scale is in under tensile stress during the cooling procedure, which leads to the cracking of $\mathrm{SiO}_{2}$ scale. Second, the $\mathrm{SiO}_{2}$ phase transformed from $\beta$ cristobalite (cubic) to $\alpha$-cristobalite (tetragonal) during the cooling process at around $573 \mathrm{~K}$ and had a volume contraction of $6 \%{ }^{[18]}$, which will also cause tensile stress in the $\mathrm{SiO}_{2}$ scale. When crack networks formed in the oxide layer after steam oxidation at $1673 \mathrm{~K}$, together with the spherical structure of SiC layer, the oxide scale could not maintain a good adhesion with the SiC. As a result, the $\mathrm{SiO}_{2}$ layer spalled off from the $\mathrm{SiC}$ layer (Fig. 2d3). Meanwhile, the cracks further provided diffusion paths of the gas, resulting in an acceleration of the oxidation rate. 
In addition, pores in the $\mathrm{SiO}_{2}$ scale were also observed after steam oxidation at high temperature (>1473 K), which can be attributed to the gaseous products (i.e., $\mathrm{CO}$ and $\mathrm{H}_{2}$ ) accumulated during the oxidation process ${ }^{[20]}$. For relatively thick oxides at high temperature steam oxidation, the inward diffusion of water vapor to react with $\mathrm{SiC}$ would be hindered. As reported in previous

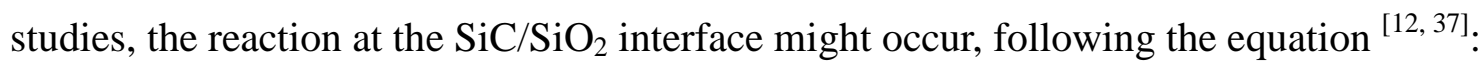

$$
\mathrm{SiC}(\mathrm{s})+2 \mathrm{SiO}_{2}(\mathrm{~s})=3 \mathrm{SiO}(\mathrm{g})+\mathrm{CO}(\mathrm{g})
$$

Including the gaseous products (i.e., $\mathrm{CO}$ and $\mathrm{H}_{2}$ ) from Eq. (11), the as-formed $\mathrm{SiO}$ and $\mathrm{CO}$ gases diffused outwards and made contributions to the formation of pores ${ }^{[34]}$, resulting in more pores at a higher temperature (Fig. 2d). Meanwhile, water vapor can decrease the viscosity and density of the $\mathrm{SiO}_{2}$ scale, which was beneficial to the outward diffusion of gas products ${ }^{[18,32]}$. Therefore, pores away from the $\mathrm{SiC} / \mathrm{SiO}_{2}$ interface were observed, especially at a higher oxidation temperature (Fig. 2d).

Meanwhile, the formation of carbon at the $\mathrm{SiC} / \mathrm{SiO}_{2}$ interface was observed above $1473 \mathrm{~K}$. The phenomenon was more significant with an increase of the oxidation temperature. It is believed that some carbon was trapped at the interface during the oxidation process due to the kinetically limited formation and removal of volatile CO molecules, especially for relatively thick oxides ${ }^{[23,24,25]}$. It was also pointed out that the limited outward diffusion of $\mathrm{CO}$ would result in a relatively high $\mathrm{CO}$ partial pressure at the $\mathrm{SiC} / \mathrm{SiO}_{2}$ interface, which in turn led to the possibility of carbon formation by increasing the carbon activity at the $\mathrm{SiC} / \mathrm{SiO}_{2}$ interface ${ }^{[39]}$. The reaction for carbon formation at the $\mathrm{SiC} / \mathrm{SiO}_{2}$ interface was reported to follow the equation below ${ }^{[12,37]}$ : 


$$
\mathrm{SiC}(\mathrm{s})+\mathrm{SiO}_{2}(\mathrm{~s})=2 \mathrm{SiO}(\mathrm{g})+\mathrm{C}(\mathrm{s})
$$

The Eq. (17) was analyzed through thermodynamic simulations with the Gibbs energy data in

previous study ${ }^{[37]}$, showing the reaction is thermodynamically favorable. The disappearance of graphitization after $1673 \mathrm{~K}$ oxidation could be due to the spallation of the partial $\mathrm{SiO}_{2}$ scale, and the carbon at the interface of $\mathrm{SiC} / \mathrm{SiO}_{2}$ could be easily oxidized above $673 \mathrm{~K}$. It was also suggested that carbon diffused towards the outer surface of the scale and gone away into the atmosphere during oxidation ${ }^{23}$.

\subsection{Effect of steam oxidation on the fracture strength of SiC layers}

After steam oxidation at above $1473 \mathrm{~K}, \mathrm{SiO}_{2}$ scale with cracks and pores was formed. Gaps between the $\mathrm{SiO}_{2}$ scale and the $\mathrm{SiC}$ layer were observed which indicate a weak interface adhesion. After steam oxidation at $1673 \mathrm{~K}$, the $\mathrm{SiO}_{2}$ scale eventually spalled from the $\mathrm{SiC}$ layer. Therefore, the mechanically weak $\mathrm{SiO}_{2}$ scale is not supposed to make significant contribution to the fracture strength of the SiC shell under crush test. The fracture patterns of both as-deposited sample and oxidized sample were investigated. For the crush test of brittle material, catastrophic failure generally occurred at the first load instability. Figure 11 shows broken specimens after crush tests, which presented the radiating cracks converging around the apex of the SiC shell. It has been confirmed that the maximum principal stress appeared around the inner-apex of the SiC shell below the loading contact area, where the cracks would initiate ${ }^{[19]}$. Transgranular cracks were observed (Fig. 11a). After steam oxidation at $1473 \mathrm{~K}$, some oxide scale spalled along the cracks and some oxide scale fragments remained overlapping with the cracks (Fig. 11b), which indicates that the cracks did not necessarily propagate from the $\mathrm{SiC}$ into the oxide layer. Therefore, it can be assumed that the oxide scale with crack networks formed on the surface had no significant effect on the crush 
test.

Previous studies showed that the difference in the fracture strength of the SiC layers in TRISO particles could be attributed to the microstructure features such as the roughness of the IPyC/SiC interface, the porosity and the grain size of the SiC layer ${ }^{[19,40]}$. Because the oxidation temperatures in this study were lower than the SiC deposition temperature (>1773 K), the SiC could maintain its microstructural stability. Thus, the effect of these factors mentioned above on the fracture strength could be assumed negligible. In addition, it has been demonstrated that high temperature thermal treatment $(<2273 \mathrm{~K})$ had negligible influence on the strength ${ }^{[41]}$. Therefore, the variation of the fracture strength of the SiC layers in this study would be mainly caused by the thickness change of the SiC layer.

Previous study showed that the fracture strength of TRISO particle was proportional to the thickness of the SiC layers, which would decrease with the decrease of the thickness of SiC layer ${ }^{[26 \text {, }}$ ${ }^{42]}$. In this study, it was found that the samples with relatively thinner layer after high temperature steam oxidation displayed lower fracture loads with a small diameter of impression (Table 2). It has been reported that the size of the indentation impression formed on the brass was almost the same as the size of the stressed area at the inner surface ${ }^{[19]}$. Since the fracture stress depends on the area of material stressed, thinner specimens had a smaller effective tested area thus tended to have higher stress concentration at the inner surface of the SiC shell ${ }^{[19]}$, where failure would initiate, and had both a smaller fracture strength and a smaller Weibull modulus. Previous study pointed out that the ratio $(r / \delta)$ of outer radius $(r)$ to the thickness of SiC layers $(\delta)$ was a critical dimensional factor for the stress distribution of the SiC shell ${ }^{[43]}$. Figure $12 \mathrm{a}$ and $12 \mathrm{~b}$ show the Weibull modulus and the mean fracture strength for the full spherical shell, which decreased linearly with the increase of the ratio $(r / \delta)$. The slopes from the linear fitting in Fig. 12 were 0.26 and 33.6 for Weibull modulus and 
mean fracture strength with $R^{2}$ (goodness of fit) of $94 \%$ and $95 \%$, respectively. The results are consistent with the previous results that showed similar values of 0.22 and 28.6 for the Weibull modulus and the mean fracture strength ${ }^{[43]}$. The decreased fracture strength of SiC layer after steam oxidation (up to $24 \%$ lower at $1673 \mathrm{~K}$ ) due to the thinning of the SiC layer would increase the failure probability for TRISO particles ${ }^{[5]}$.

\section{Conclusions}

The steam oxidation of SiC layers in TRISO particles was investigated at a temperature range of 1173-1673 K in water vapor-argon atmosphere with a total pressure of 1 bar. The oxidation kinetics model of was proposed. The fracture strengths after steam oxidation were also measured.

The presence of water vapor not only increased the crystallization of the amorphous $\mathrm{SiO}_{2}$ oxide scale, but also increased the oxidation rate of the SiC layer. The SiC layer has a good steam oxidation resistance below $1273 \mathrm{~K}$. Above $1373 \mathrm{~K}$, the oxidation kinetics of SiC follows the parabolic law. The calculated activation energy was $103 \pm 11 \mathrm{~kJ} / \mathrm{mol}$, suggesting that the rate determine step of the oxidation is the diffusion of water vapor molecules in the oxide scale. The fracture strength decreased with the increase of the oxidation temperature mainly due to the thinning of the SiC layer.

\section{Acknowledgments}

This research was supported by the Natural Science Foundation of China (No.51472157), the “1000 Plan Program”, and the Program for Professor of Special Appointment (Eastern Scholar) at Shanghai Institutions of Higher Learning (No. SHDP201303). 


\section{References}

${ }^{1}$ K. Sawa and S. Ueta, "Research and development on HTGR fuel in the HTTR project," Nucl. Eng. Des., 233 [1] 163-72 (2004).

${ }^{2}$ L. L. Snead, T. Nozawa, Y. Katoh, T. S. Byun, S. Kondo, and D. A. Petti, "Handbook of SiC properties for fuel performance modeling," J. Nucl. Mater., 371 [1-3] 329-77 (2007).

${ }^{3}$ C. I. Contescu, R. W. Mee, P. Wang, A. V. Romanova, and T. D. Burchell, "Oxidation of PCEA nuclear graphite by low water concentrations in helium," J. Nucl. Mater., 453 [1] 225-32 (2014).

${ }^{4}$ Y. Wang, Y. Zheng, F. Li, and L. Shi, "Analysis on blow-down transient in water ingress accident of high temperature gas-cooled reactor," Nucl. Eng. Des., 271 404-10 (2014).

${ }^{5}$ G. K. Miller, D. A. Petti, J. T. Maki, and D. L. Knudson, "An evaluation of the effects of SiC layer thinning on failure of TRISO-coated fuel particles," J. Nucl. Mater., 355 [1-3] 150-62 (2006).

${ }^{6}$ J. B. Malherbe, "Diffusion of fission products and radiation damage in SiC," J. Phys. D: Appl. Phys., 46 [47] 473001 (2013).

${ }^{7}$ K. A. Terrani, L. L. Snead, and J. C. Gehin, "Microencapsulated fuel technology for commercial light water and advanced reactor application," J. Nucl. Mater., 427 [1] 209-24 (2012). 
${ }^{8}$ S. Singhal, "Effect of Water Vapor on the Oxidation of Hot-Pressed Silicon Nitride and Silicon Carbide," J. Am. Ceram. Soc., 59 [1-2] 81-2 (1976).

${ }^{9}$ T. Narushima, T. Goto, Y. Iguchi, and T. Hirai, "High-Temperature Oxidation of Chemically Vapor-Deposited Silicon Carbide in Wet Oxygen at 1823 to 1923 K," J. Am. Ceram. Soc., 73 [12] 3580-4 (1990).

${ }^{10}$ K. L. More, P. F. Tortorelli, L. R. Walker, N. Miriyala, J. R. Price, and M. Roode, "HighTemperature Stability of SiC-Based Composites in High-Water-Vapor-Pressure Environments," J. Am. Ceram. Soc., 86 [8] 1272-81 (2003).

${ }^{11}$ E. López-Honorato, P. Meadows, J. Tan, and P. Xiao, "Control of stoichiometry, microstructure, and mechanical properties in SiC coatings produced by fluidized bed chemical vapor deposition," $J$. Mater. Res., 23 [06] 1785-96 (2008).

${ }^{12}$ R. Liu, B. Liu, K. Zhang, M. Liu, Y. Shao, and C. Tang, "High temperature oxidation behavior of SiC coating in TRISO coated particles," J. Nucl. Mater., 453 [1-3] 107-14 (2014).

${ }^{13}$ K. A. Terrani and C. M. Silva, "High temperature steam oxidation of SiC coating layer of TRISO fuel particles," J. Nucl. Mater., 460 160-5 (2015).

${ }^{14}$ E. López-Honorato, J. Tan, P. Meadows, G. Marsh, and P. Xiao, "TRISO coated fuel particles 
with enhanced SiC properties," J. Nucl. Mater., 392 [2] 219-24 (2009).

${ }^{15}$ E. J. Opila, D. S. Fox, and N. S. Jacobson, "Mass spectrometric identification of Si-OH (g) species from the reaction of silica with water vapor at atmospheric pressure," J. Am. Ceram. Soc., 80 [4] 1009-12 (1997).

16 E. J. Opila, "Oxidation Kinetics of Chemically Vapor-Deposited Silicon Carbide in Wet Oxygen," J. Am. Ceram. Soc., 77 [3] 730-6 (1994).

${ }^{17}$ K. A. Terrani, B. A. Pint, C. M. Parish, C. M. Silva, L. L. Snead, and Y. Katoh, "Silicon carbide oxidation in steam up to 2 MPa," J. Am. Ceram. Soc., 97 [8] 2331-52 (2014).

${ }^{18}$ Cheng, T. and Tortorelli, P. F. (2013), Silicon Carbide Oxidation in High-Pressure Steam. J. Am. Ceram. Soc., 96: 2330-2337. doi:10.1111/jace.12328

${ }^{19}$ T. S. Byun, J. D. Hunn, J. H. Miller, L. L. Snead, and J. W. Kim, "Evaluation of Fracture Stress for the SiC Layer of TRISO-Coated Fuel Particles Using a Modified Crush Test Method," Int. J. Appl. Ceram. Tec., 7 [3] 327-37 (2010).

${ }^{20}$ P. F. Tortorelli and K. L. More, "Effects of High Water-Vapor Pressure on Oxidation of Silicon Carbide at $1200{ }^{\circ}$ C," J. Am. Ceram. Soc., 86 [8] 1249-55 (2003). 
${ }^{21}$ H. Mi, S. Mikael, T. Allen, K. Sridharan, D. Butt, J. P. Blanchard, and Z. Ma, "Monitoring the oxidation of nuclear fuel cladding using Raman spectroscopy," J. Nucl. Mater., 445 [1] 7-11 (2014).

${ }^{22}$ M. A. Pimenta, G. Dresselhaus, M. S. Dresselhaus, L. Cancado, A. Jorio, and R. Saito, "Studying disorder in graphite-based systems by Raman spectroscopy," Phys. Chem. Chem. Phys., 9 [11] 1276-90 (2007).

${ }^{23}$ J. Li, P. Eveno, and A. Huntz, "Oxidation of SiC," Mater. Corros., 41 [12] 716-25 (1990).

${ }^{24}$ K. Chang, N. Nuhfer, L. Porter, and Q. Wahab, "High-carbon concentrations at the silicon dioxide-silicon carbide interface identified by electron energy loss spectroscopy," Appl. Phys. Lett., 772186 (2000).

${ }^{25}$ R. Berjoan, J. Rodriguez, and F. Sibieude, "AES Study of the $\mathrm{SiO}_{2} / \mathrm{SiC}$ Interface in the Oxidation of CVD $\beta$-SiC," Surf. Sci., 271 [1] 237-43 (1992).

${ }^{26}$ R. Cromarty, G. van Rooyen, and J. de Villiers, "Crush strength of silicon carbide coated TRISO particles: Influence of test method and process variables," J. Nucl. Mater., 445 [1] 30-6 (2014).

${ }^{27}$ G. T. Van Rooyen, R. Du Preez, J. De Villiers, and R. Cromarty, "The fracture strength of TRISO-coated particles determined by compression testing between soft aluminium anvils," J. Nucl. 
Mater., 403 [1] 126-34 (2010).

${ }^{28}$ R.J. Roark, W.C. Young, "Formulas for Stress and Strain," McGraw-Hill Book Co., Fifth Eds, New York, 1974.

${ }^{29}$ G. Eriksson and K. Hack, "ChemSage-a computer program for the calculation of complex chemical equilibria," Metall. Trans. B, 21 [6] 1013-23 (1990).

${ }^{30}$ E. J. Opila, "Variation of the Oxidation rate of silicon carbide with water-vapor pressure," $J$. Am. Ceram. Soc., 82 [3] 625-36 (1999).

31 R. C. Robinson and J. L. Smialek, "SiC recession caused by $\mathrm{SiO}_{2}$ scale volatility under combustion conditions: I, experimental results and empirical model," J. Am. Ceram. Soc., 82 [7] 1817-25 (1999).

${ }^{32}$ E. J. Opila and R. E. Hann, "Paralinear oxidation of CVD SiC in water vapor," J. Am. Ceram. Soc., 80 [1] 197-205 (1997).

${ }^{33}$ N. S. Jacobson, E. J. Opila, and K. N. Lee, "Oxidation and corrosion of ceramics and ceramic matrix composites," Curr. Opin. Solid St. M., 5 [4] 301-09 (2001).

${ }^{34}$ N. S. Jacobson, "Corrosion of Silicon - Based Ceramics in Combustion Environments," J. Am. 
Ceram. Soc., 76 [1] 3-28 (1993).

${ }^{35}$ B. E. Deal and A. S. Grove, "General Relationship for the Thermal Oxidation of Silicon," $J$. Appl. Phys., 36 [12] 3770-78 (1965).

${ }^{36}$ E. J. Opila, "Influence of Alumina Reaction Tube Impurities on the Oxidation of ChemicallyVapor-Deposited Silicon Carbide," J. Am. Ceram. Soc., 78 [4] 1107-10 (1995).

${ }^{37}$ G. Wang, G. Lu, B. Pei, and A. Yu, "Oxidation mechanism of $\mathrm{Si}_{3} \mathrm{~N}_{4}$-bonded $\mathrm{SiC}$ ceramics by CO, $\mathrm{CO}_{2}$ and steam," J. mater. Sci., 33 [5] 1309-17 (1998).

${ }^{38} \mathrm{X}$. Yin, L. Cheng, L. Zhang, and Y. Xu, "Oxidation behaviors of C/SiC in the oxidizing environments containing water vapor," Mater. Sci. Eng.: A, 348 [1-2] 47-53 (2003).

${ }^{39} \mathrm{H}$. Katsui, M. Oguma, and T. Goto, "Carbon Interlayer Between $\mathrm{CVD} \mathrm{SiC}$ and $\mathrm{SiO}_{2}$ in High-Temperature Passive Oxidation," J. Am. Ceram. Soc., 97 [5] 1633-7 (2014).

${ }^{40}$ S. J. Xu, J. G. Zhou, B. Yang, and B. Z. Zhang, "Effect of deposition temperature on the properties of pyrolytic SiC," J. Nucl. Mater., 224 [224] 12-6 (1995).

${ }^{41}$ I. J. V. Rooyen, J. H. Neethling, and P. M. V. Rooyen, "The influence of annealing temperature on the strength of TRISO coated particles," J. Nucl. Mater., 402 [402] 136-46 (2010). 
${ }^{42}$ W. Lackey, D. Stinton, L. Davis, and R. Beatty, "Crushing strength of high-temperature gascooled reactor fuel particles," Nucl. Technol., 31 [2] 191-201 (1976).

${ }^{43}$ H. Zhang, "Mechanical and microstructural study of silicon carbide and pyrolytic carbon coatings in TRISO fuel particles," PhD Thesis. University of Manchester. 2012. 


\section{Figure Captions}

Fig. 1 Schematic illustration of the modified crush test system for hemispherical SiC shell.

Fig. 2 SEM images of surface morphology and fracture cross-sections of (a)-(d) steam oxidation for $24 \mathrm{~h}$ under different temperatures and (e) oxidation in dry air at $1473 \mathrm{~K}$ for $24 \mathrm{~h}$, in which the insert c3 shows EDS results from the surface and d3 shows partial spallation of $\mathrm{SiO}_{2}$ scale at $1673 \mathrm{~K}$.

Fig. 3 XRD patterns of TRISO particles: (a) includes as-deposited sample, the samples after steam oxidation for $24 \mathrm{~h}$ at $1273 \mathrm{~K}-1673 \mathrm{~K}$ and the samples after oxidation in dry air for $24 \mathrm{~h}$ at $1473 \mathrm{~K}$ and (b) amplifies XRD patterns from 20 degree to 28 degree.

Fig. 4 Raman spectra measured from the surface of SiC layer in TRISO particles: (a) includes asdeposited sample, the samples after steam oxidation for $24 \mathrm{~h}$ at $1273 \mathrm{~K}-1673 \mathrm{~K}$ and the samples after oxidation for $24 \mathrm{~h}$ in dry air for $24 \mathrm{~h}$ at $1473 \mathrm{~K}$ and (b) amplifies Raman spectra from 1200 $\mathrm{cm}^{-1}$ to $1850 \mathrm{~cm}^{-1}$.

Fig. 5 The thickness of $\mathrm{SiO}_{2}$ layer as a function of oxidation time under different temperatures in steam atmosphere.

Fig. 6 Weibull plots for the measured fracture load. 
Fig. 7 The measured fracture load as a function of the SiC thickness compared with previous study using different insert metal for the crush test.

Fig. 8 The calculated local fracture strength of SiC shells in the form of Weibull distribution for different steam oxidation treatment samples.

Fig. 9 Weibull distribution of the calculated fracture strength for full spherical shells for different steam oxidation treatment samples.

Fig. 10 Arrhenius plots of parabolic oxidation rate constant $\left(k_{p}\right)$ as a function of temperature for the SiC layer oxidation in steam atmosphere.

Fig. 11 Crack patterns of the broken specimens of (a) as-deposited sample and (b) sample after steam oxidation at $1473 \mathrm{~K}$ after crush tests.

Fig. 12 The relationship of (a) the modulus derived from local fracture strength and (b) the mean fracture strength for full spherical shell with the ratio of outer radius to thickness of SiC layer, respectively. 


\section{Table Captions}

Table 1 Summarized basic parameters for the steam oxidation setup

Table 2 Summarized results of crush tests with the Weibull modulus given in brackets of SiC shells after steam oxidation at different temperatures for $24 \mathrm{~h}$

Table 3 A summary of parabolic oxidation rates of SiC layers at different temperatures 
Fig. 1

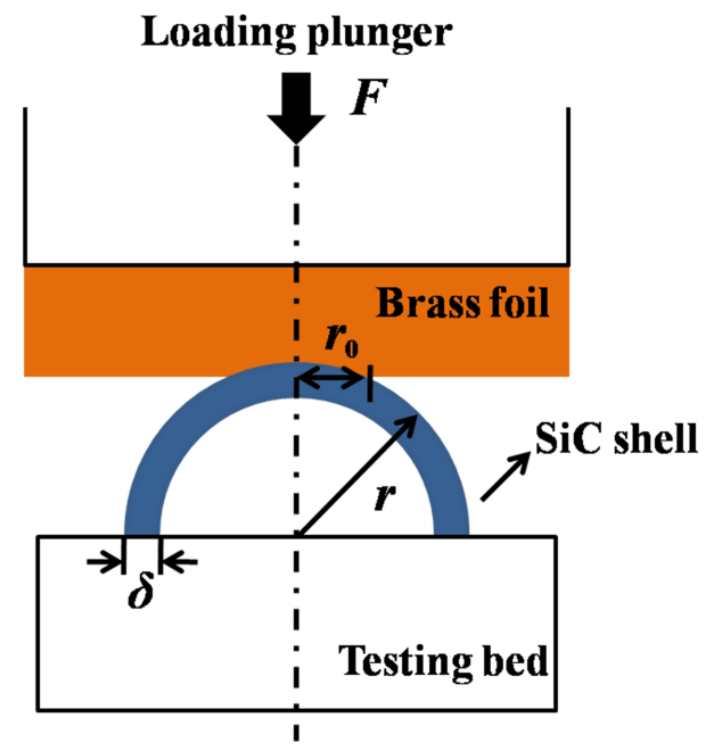


Fig. 2

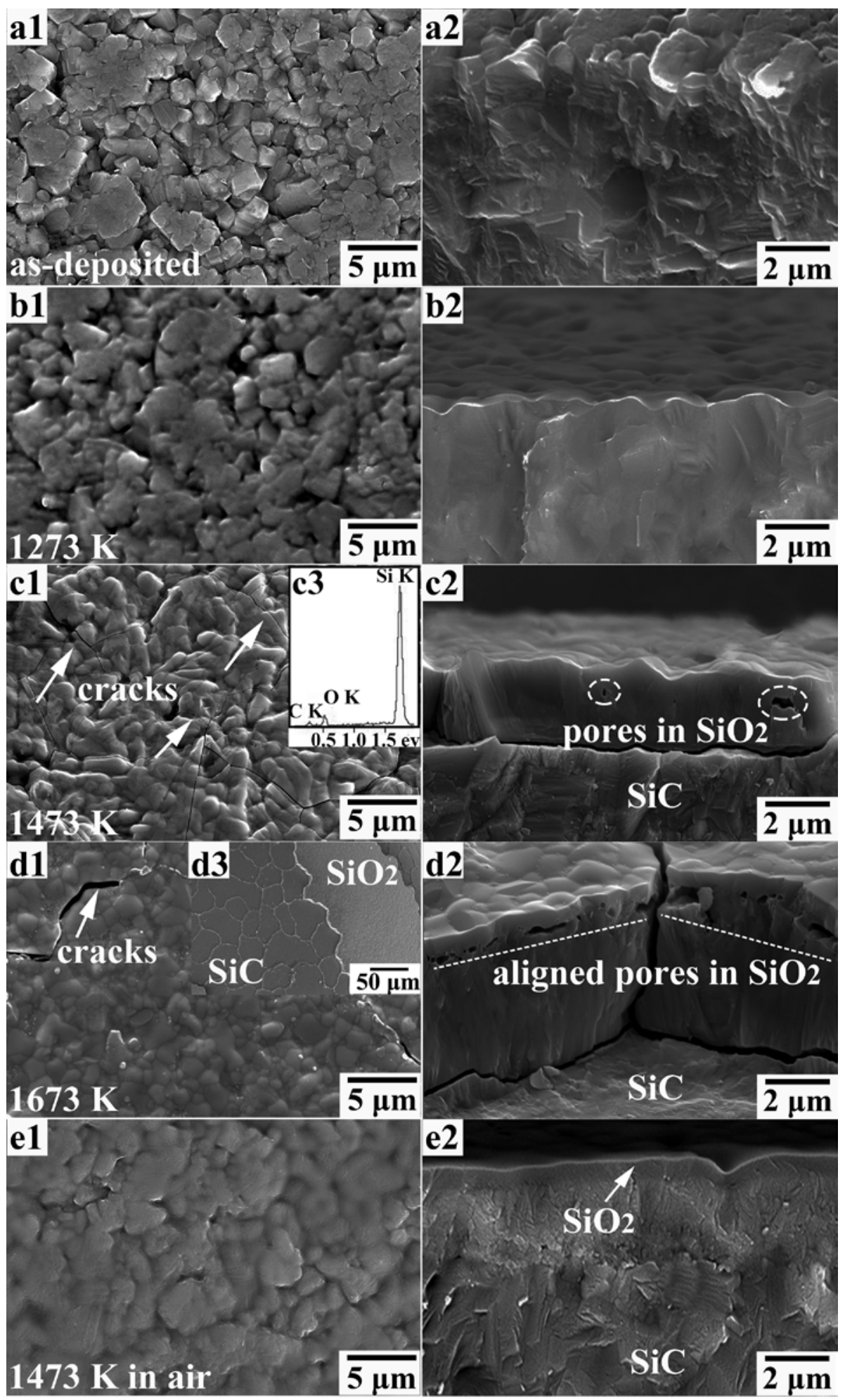


Fig. 3
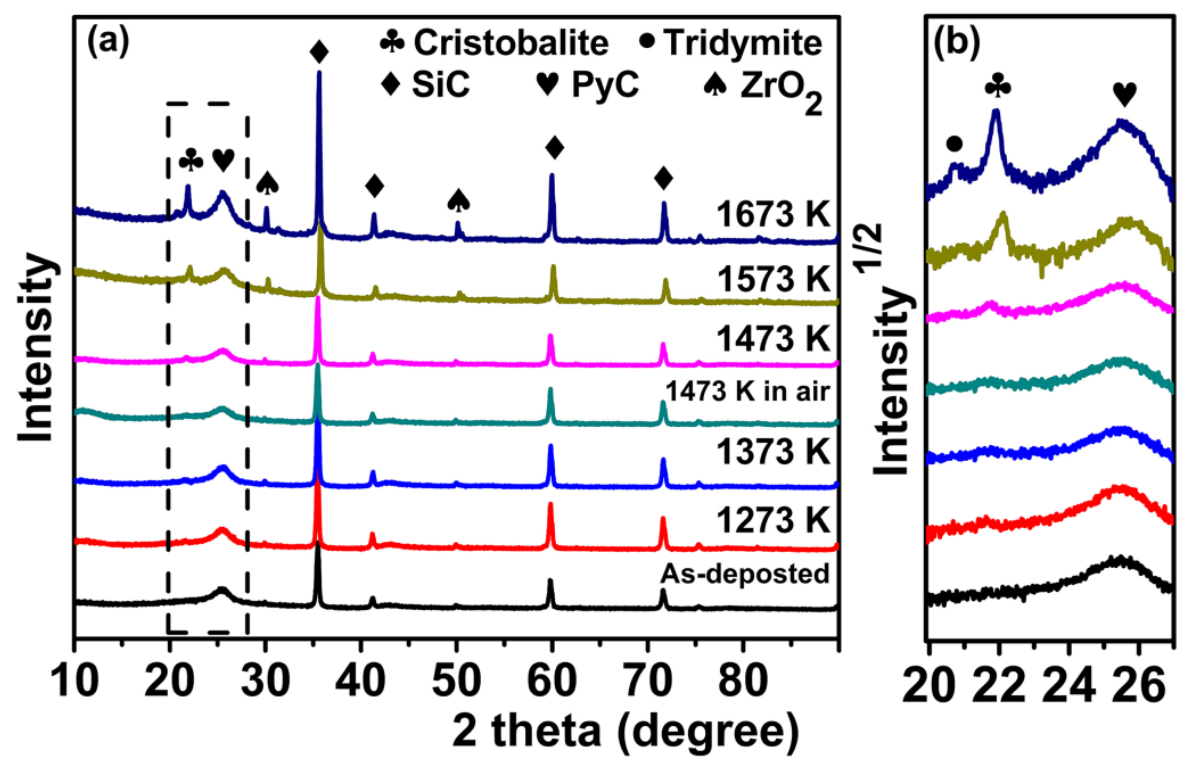
Fig. 4

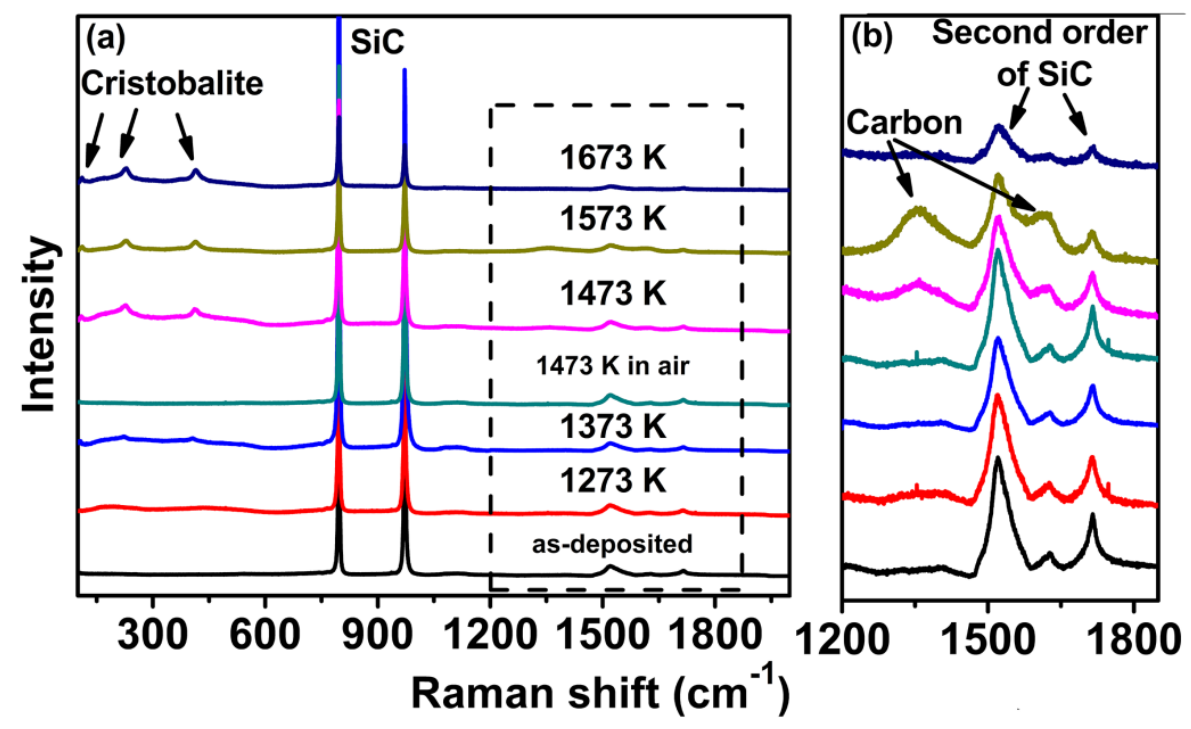


Fig. 5

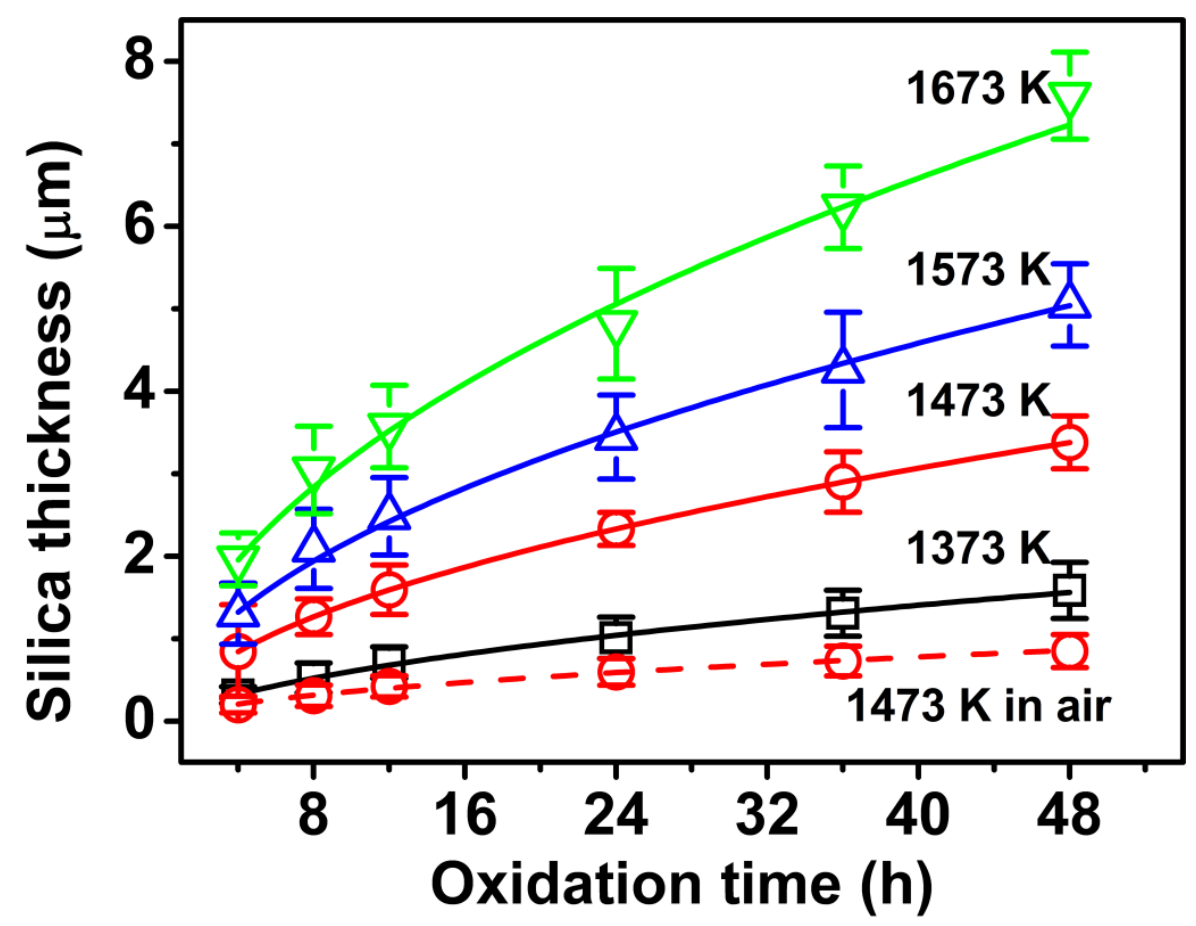


Fig. 6

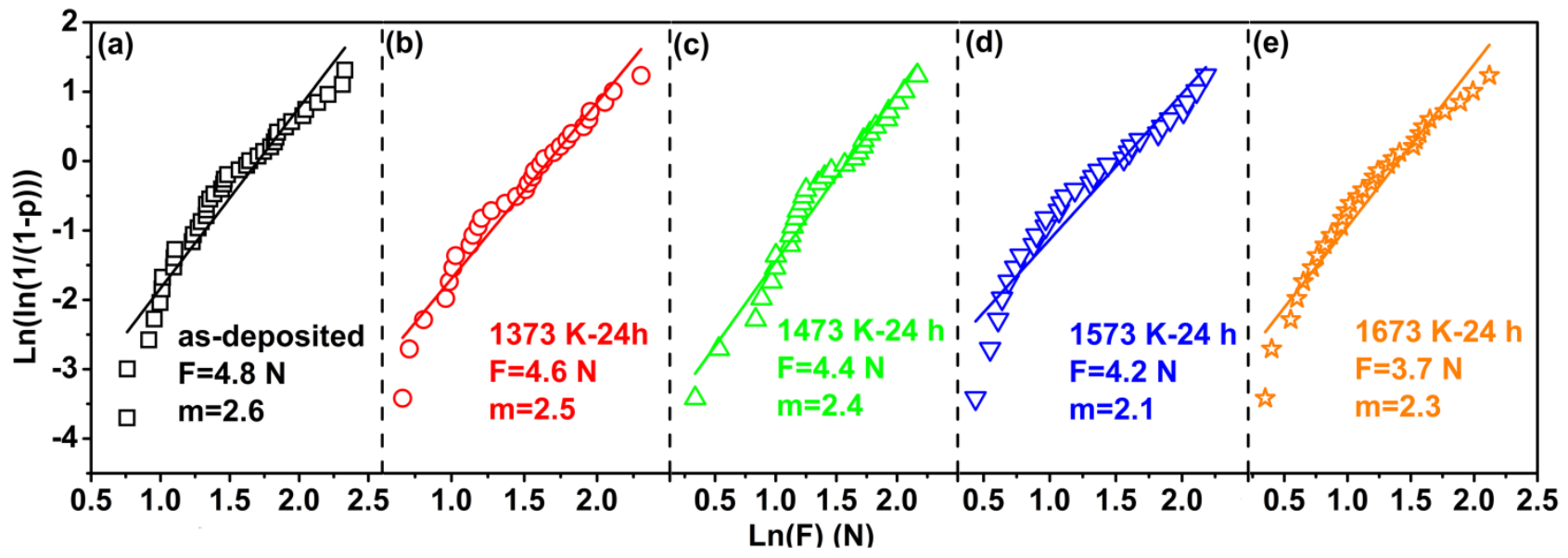


Fig. 7

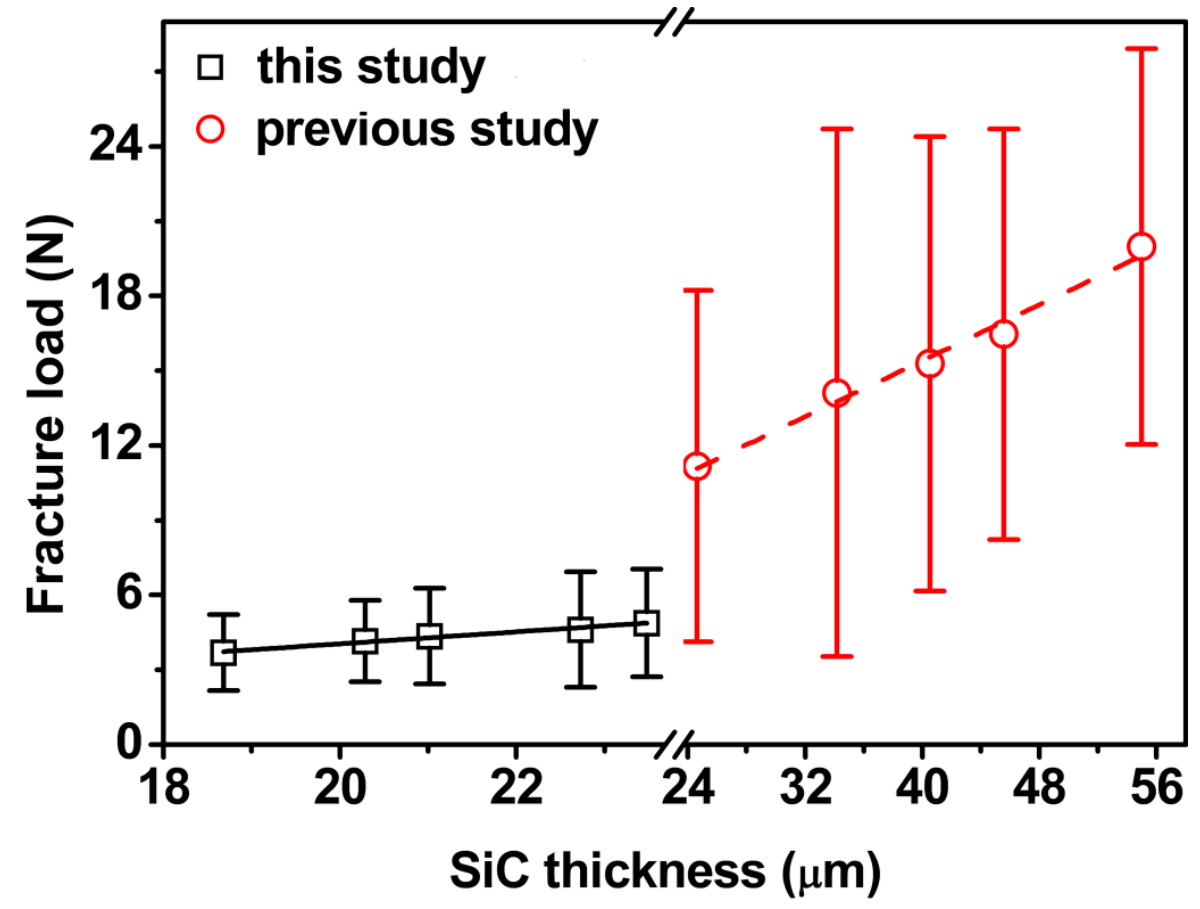


Fig. 8

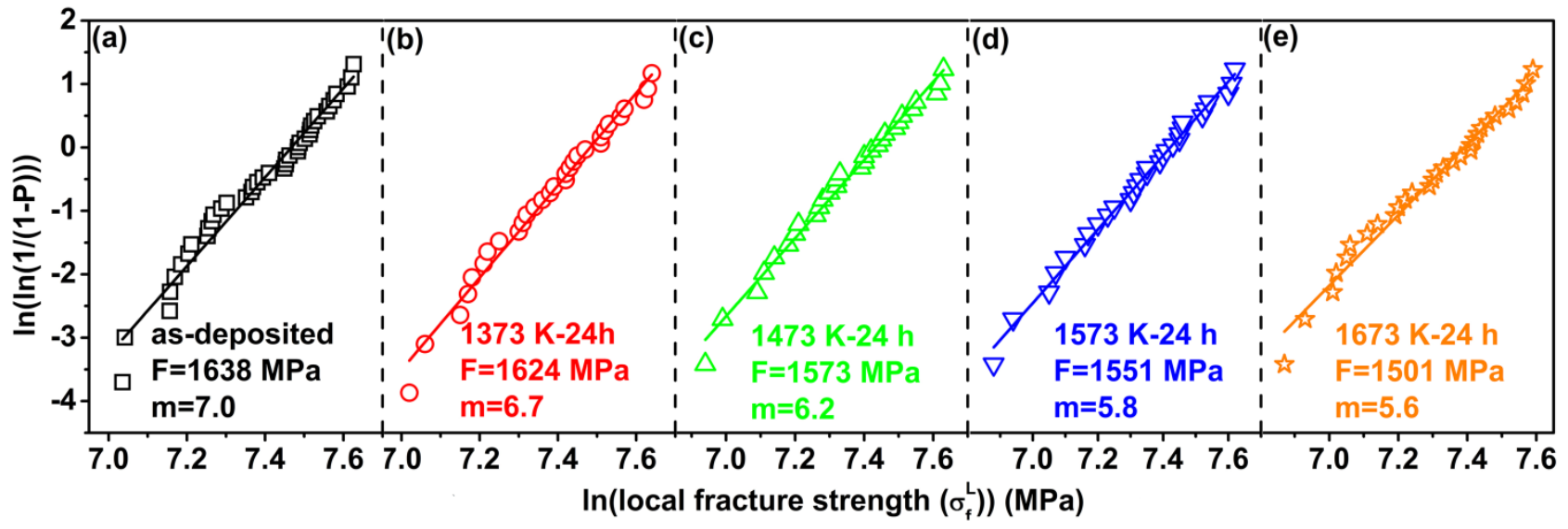


Fig. 9

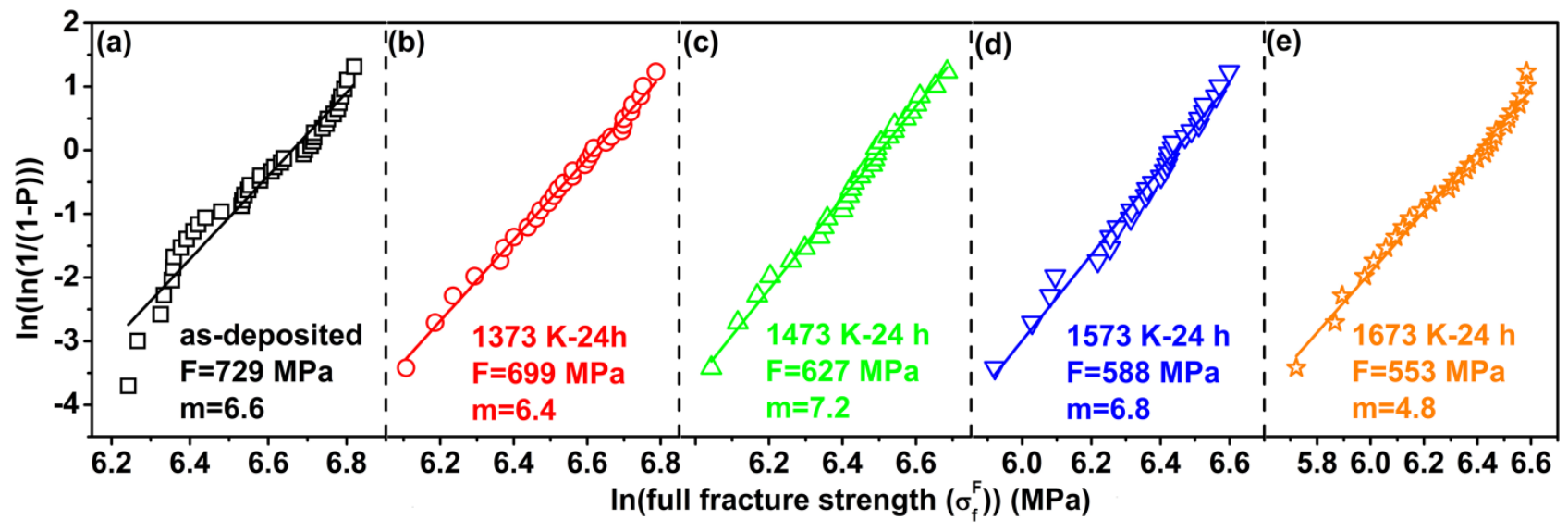


Fig. 10

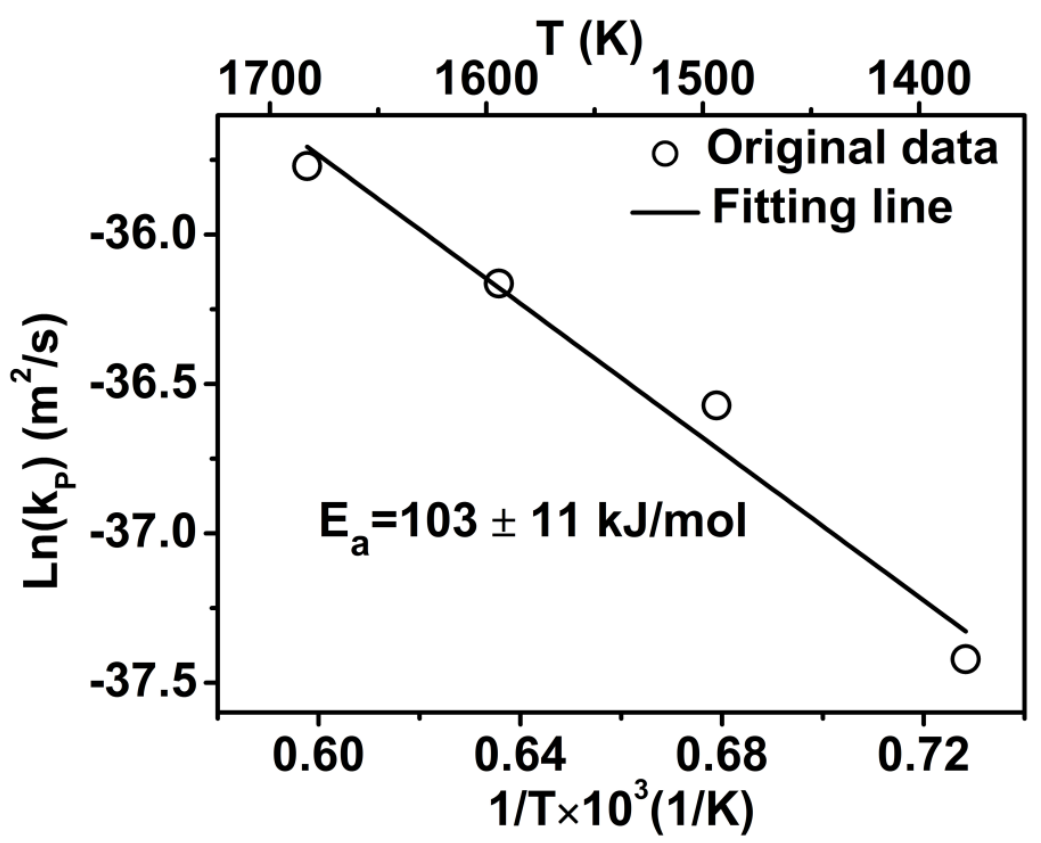


Fig. 11
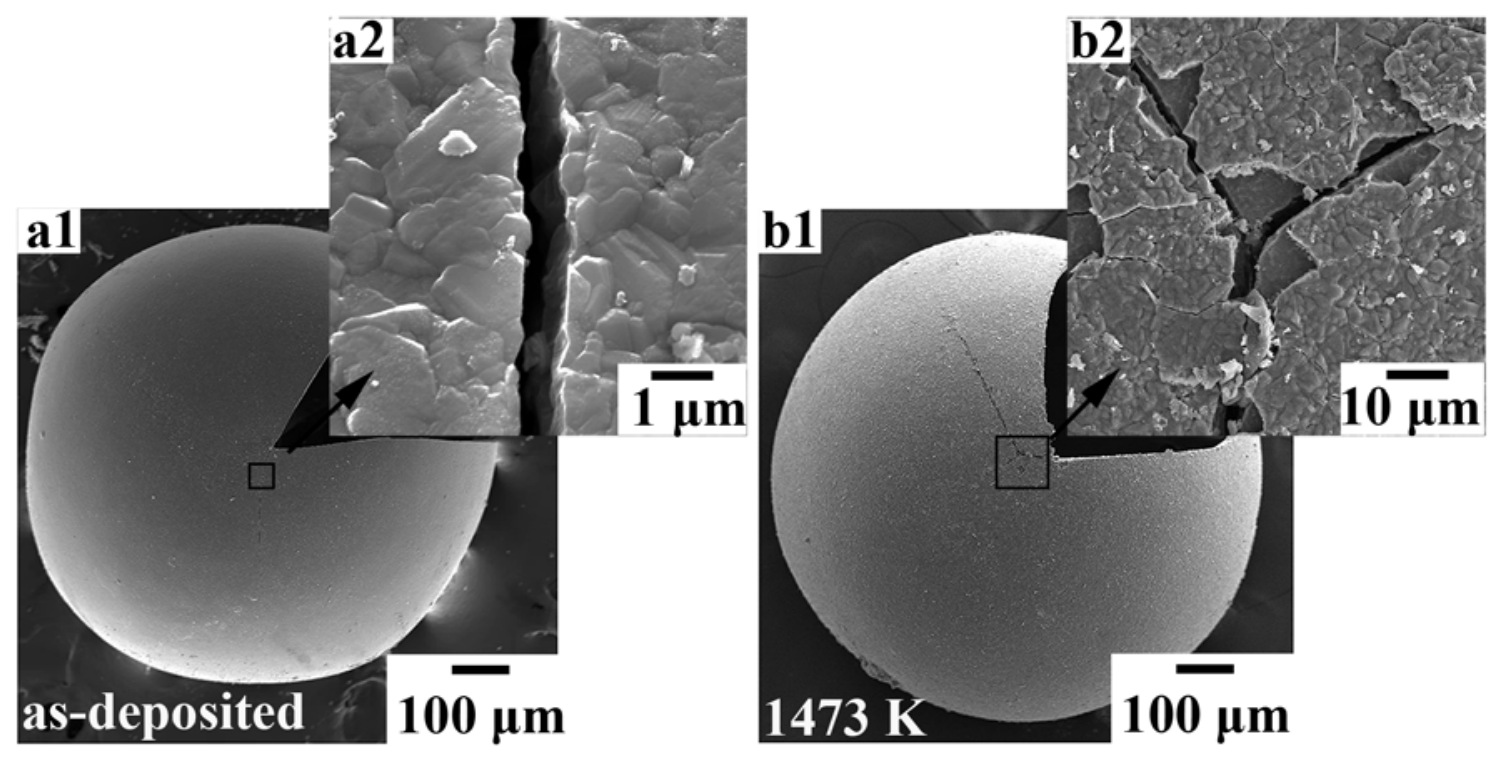
Table 1 Summarized basic parameters for the steam oxidation setup

\begin{tabular}{|c|c|c|c|c|c|c|c|c|}
\hline & \multicolumn{3}{|c|}{ Alumina tube } & \multirow[b]{2}{*}{$\begin{array}{l}\text { Hot } \\
\text { zone } \\
(\mathrm{mm})\end{array}$} & \multirow[b]{2}{*}{$\begin{array}{c}\text { The oil bath } \\
\text { temperature } \\
\text { (K) }\end{array}$} & \multicolumn{3}{|c|}{ The flow rate $\left(\times 10^{-4} \mathrm{~m} / \mathrm{s}\right)$} \\
\hline & $\begin{array}{c}\text { Inner cross } \\
\text { sectional } \\
\text { area }\left(\mathrm{m}^{2}\right) \\
\end{array}$ & $\begin{array}{l}\text { Length } \\
\text { (m) }\end{array}$ & $\begin{array}{c}\text { Thickness } \\
\text { (mm) }\end{array}$ & & & Argon & $\begin{array}{l}\text { Water } \\
\text { vapor }\end{array}$ & $\begin{array}{c}\text { Gas } \\
\text { mixture }\end{array}$ \\
\hline Parameters & $3.8 \times 10^{-3}$ & 1 & 5 & 20 & 363 & 8.7 & 5.2 & 14 \\
\hline
\end{tabular}

Table 2 Summarized results of crush tests (with the Weibull modulus given in brackets) of SiC shells after steam oxidation at different temperatures for $24 \mathrm{~h}$

\begin{tabular}{cccccc}
\hline Sample & $2 r_{0}(\mu \mathrm{m})$ & $F(\mathrm{~N})$ & $\sigma_{f}^{L}(\mathrm{MPa})$ & $\begin{array}{c}\text { Scaling factor } \\
\text { for Size effect }\end{array}$ & $\sigma_{f}^{F}(\mathrm{MPa})$ \\
\hline As-deposited & 120.9 & $4.8(2.6)$ & $1638(7.0)$ & 2.3 & $729(6.6)$ \\
1373K-24h & 119.2 & $4.6(2.5)$ & $1624(6.7)$ & 2.3 & $699(6.4)$ \\
1473K-24h & 114.8 & $4.4(2.4)$ & $1573(6.2)$ & 2.5 & $627(7.2)$ \\
1573K-24h & 112.9 & $4.2(2.1)$ & $1551(5.8)$ & 2.6 & $588(6.8)$ \\
1673K-24h & 107.1 & $3.7(2.3)$ & $1501(5.6)$ & 2.7 & $553(4.8)$ \\
\hline
\end{tabular}

Table 3 A summary of parabolic oxidation rates of the SiC layers at different temperatures

\begin{tabular}{ccc}
\hline \multirow{2}{*}{ Oxidation temperature $(\mathrm{K})$} & \multicolumn{2}{c}{ Parabolic rate $\left(k_{p}\right)\left(\times 10^{-16} \mathrm{~m}^{2} / \mathrm{s}\right)$} \\
\cline { 2 - 3 } & This study & Previous study \\
\hline 1373 & 0.56 & - \\
1473 & 1.31 & 1.39 \\
1573 & 1.97 & 2.73 \\
1673 & 2.92 & 6.91 \\
1473 (in air) & 0.33 & - \\
\hline
\end{tabular}

